\title{
A WORLD OF CONNECTIONS! SCHOOL PSYCHOLOGISTS AS COMMUNICATORS, COLLABORATORS, ORGANIZERS AND MENTAL HEALTH ADVOCATES
}

\section{Marta Kolaříková}

On July 20-23, 2016, the 38th ISPA Conference was held in Amsterdam under the name: "School Psychology 3.0: A World of Connections. School Psychologists as Communicators, Collaborators, Organizers and Mental Health Advocates." It was attended by 571 participants from 54 countries of the world.

The main topic of the conference was inspired by the model of seven roles of the school psychologist by Peter Farrel and his colleagues.

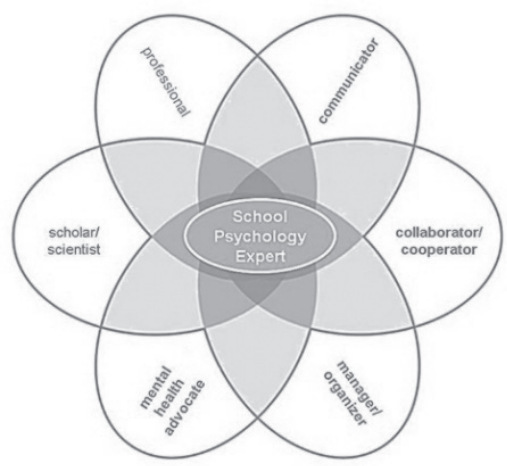

Using the model, we can distinguish seven professional roles / competency areas for the School Psychologist:

1. Expert

2. Communicator

3. Collaborator

4. Organizer

5. Mental Health Advocate

6. Scholar/scientist

7. Professional

In each of these roles, the school psychologist makes connections to pupils, teachers, parents, colleagues, the school management, town councils, medical doctors, social workers, etc. The chosen theme also highlights the fact that School Psychologists work within a system.

On Wednesday, 20 July, several Pre conference workshops took place, with focus on different topics. I attended a very interesting workshop of Elaine Fletcher-Janzen \& Pip McGirl on the topic: A Biopsychosocial Approach to the Assessment and Treatment of Trauma and Atachment Issues. In the evening, an "Opening ceremony" was organized for all conference participants in the beautiful environment of the Royal Tropical Institute; the evening culminated in the Welcome reception at which the conference participants 
discussed informally about their countries, the problems of school psychology, education systems and consultancy from many perspectives. Unfortunately, I was the only participant from the Czech Republic.

Both Thursday and Friday were full of events at the conference. All expert lectures took place in a very pleasant environment of the University of Amsterdam, which has a beautiful campus in the centre of Amsterdam with some new state of the art conference halls.

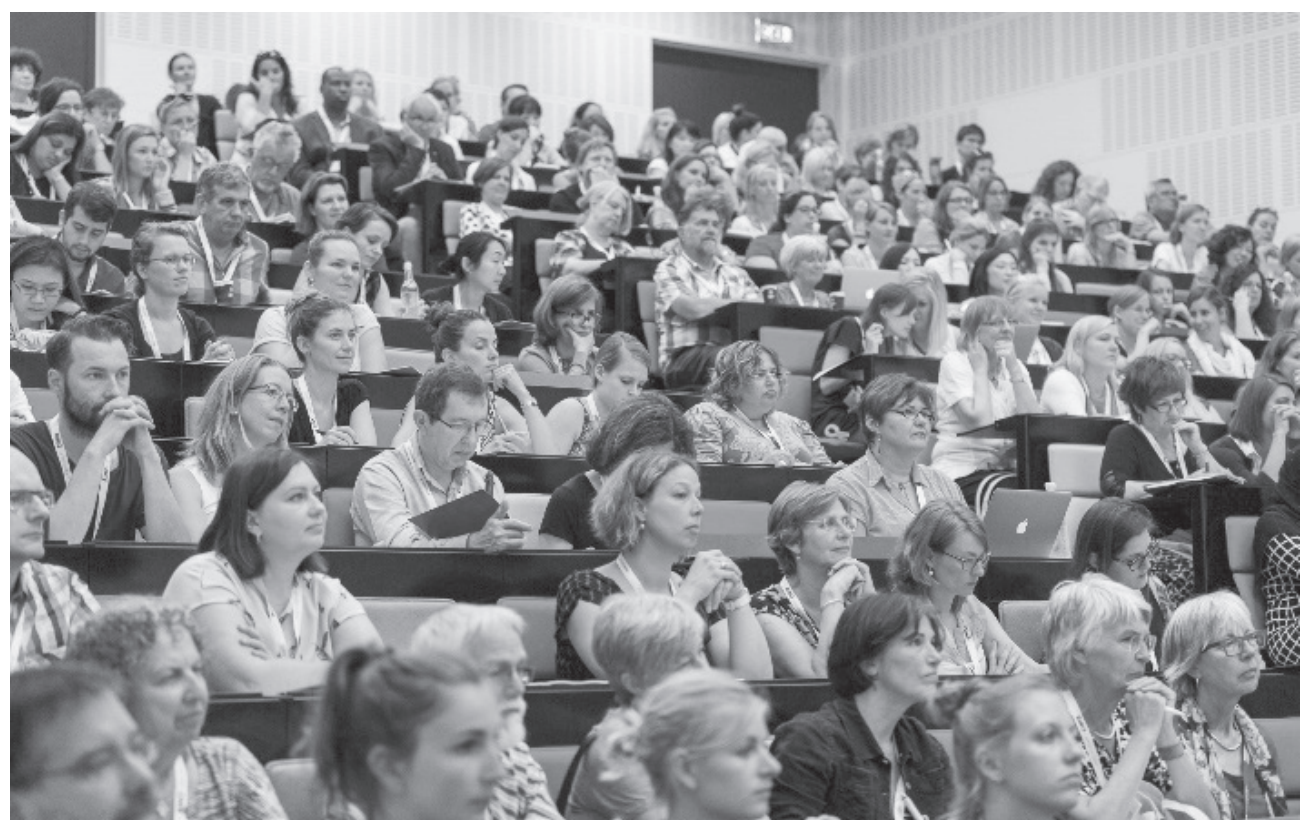

The papers were divided into topic sections that took ninety minutes each; then a lecture of the keynote speaker followed; after lunch, there were INTERACTION GROUPS followed by a lecture of another keynote speaker and by another topic section. At the end of the day, structured presentations of posters took place, with discussions on the individual topics that also enjoyed great interest, until late hours.

The lectures of the keynote speakers enjoyed great interest of the audience gathered in full conference rooms and in rooms to which the lectures were transmitted with the help of the technology.

The topics of the keynote speakers referred to current trends of research and practice. The following keynote speakers presented their lectures:

Drs. Noëlle Pameijer (School psychologist at a tailored education and inclusion center Unita in Hilversum, Netherlands) with the topic: "Needs-based Assessment and Interventions",

Prof. Dr. Alexander Minnaert (University of Groningen) with the topic: "Learning and Education in $21^{\text {st }}$ Century Schools: Strengths and Challenges..." 
Dr. Bonnie Nastasi (Tulane University, New Orleans, LA, USA) with the topic: "The School Psychologist as Mental Health Advocate"

Prof. Dr. Han van der Maas (University of Amsterdam) with the topic: "Adaptive Education" Each 90-minute topic section consisted of presentations from different areas, e.g. Prevention, mental health promotion, Effective strategies that promote wellbeing and resilience, Screening programs that identify students with mental health needs, Crisis intervention, School and systems organizations, Home - school - community collaboration, Working with children and families from culturally diverse communities, Family involvement in education, Methods to facilitate communication with students, school personnel, families, community professionals and others.

The conference was really contributive and it emphasized one important fact. In different countries, on different continents, the experts face the issue of challenging work with children and young people endangered by exclusion through preventive activities and their real effect on the quality of life, but also through crisis management of schools. Regardless of different levels of cooperation between state, school and family, both the active and the passive conference participants agreed on one common point: it is important to be in contact not only with other experts but primarily with the families and the children whose quality of life is in question. Although I did not participate in the conference with my own paper, I established cooperation with important experts who agreed to become members of the editorial board of the Social Pathology and Prevention Magazine. They are:

Kelly Edyburn, M. Ed. from University of California, Santa Barbara, Gevirtz Graduate School of Education, Department of Counseling, Clinical, and School Psychology, USA Junko lida, PhD. Assoc. Professor from Education Bureau of the Laboratory Schools, Faculty of Human Science, University of Tsukuba, Japan

Assoc. Prof. Éva Szabó, PhD. From University of Szeged, Faculty of Arts, Institute of Psychology, Department of Social and Developmental Psychology, Hungary

Assoc. Prof. Ala Petrulyte from Lithuania University of Educational Sciences, Faculty of Education, Department of Developmental and Educational Psychology, Lithuania We are looking forward to further cooperation.

\section{Author}

Mgr. et Mgr. Marta Kolařiková, Ph.D.

Faculty of Public Policies, Silesian University in Opava

The Institute of Pedagogical and Psychological Sciences

Bezručovo nám. 885/14, 74601 Opava, The Czech Republic

marta.kolarikova@fvp.slu.cz 